\title{
In reply: Lingual traction to aid fiberoptic intubation
}

\author{
Yiu-Hei Ching $\cdot$ Enrico M. Camporesi • \\ Devanand Mangar
}

Received: 15 November 2014 / Accepted: 20 November 2014 / Published online: 13 January 2015

(C) Japanese Society of Anesthesiologists 2015

Keywords Lingual traction · Fiberoptic intubation · Difficult airway

To the Editor:

We thank Dr. Liu et al. [1] for the comments. Our main objective was to evaluate the effects of lingual traction on fiberoptic intubation (FOI) in patients with difficult airways [2]. Accordingly, predictors of difficult airways were not evaluated, but were referred to when determining subject eligibility. We used a 6.0-mm outer-diameter fiberoptic bronchoscope, and endotracheal tubes (ETT) with internal diameters of $7.0 \mathrm{~mm}$ in females and $8.0 \mathrm{~mm}$ in males. While we agree that positioning the ETT bevel posteriorly can improve the success of FOI, this difference is negligible in our experience. We also agree that not controlling for external laryngeal manipulation, jaw thrust, and head/ neck position was a significant limitation of our study that created a performance bias as acknowledged in our manuscript. Future studies should control for these factors.

The authors refer to the study by Durga et al. that failed to produce full airway clearance with lingual traction and FOI in a significant number of patients [3]. However, this study excluded any patients with known or suspected difficult intubation.

As Liu et al. discuss, our results suggest that using lingual traction with the Williams airway can provide a higher first attempt FOI success rate than with the Williams airway alone. However, the benefit of lingual traction for FOI in patients with difficult airways is evident from our study. We agree and recommend using the Williams airway in these situations.

Acknowledgments Funding for this study was received from Florida Gulf-to-Bay Anesthesiology Associates. The authors do not have any commercial or non-commercial affiliations, conflicts of interests, or any other associates to disclose.

\section{References}

1. Liu JH, Xue FS, Liao X. Lingual traction to aid fiberoptic intubation. J Anesth. 2014. doi:10.1007/s00540-014-1931-6.

2. Ching YH, Karlnoski RA, Chen H, Camporesi EM, Shah VV, Padhya TA, Mangar D. Lingual traction to facilitate fiber-optic intubation of difficult airways: a single-anesthesiologist randomized trial. J Anesth. 2014. doi:10.1007/s00540-014-1920-9.

3. Durga VK, Millns JP, Smith JE. Manoeuvres used to clear the airway during fibreoptic intubation. Br J Anaesth. 2001;87:207-11.

Y.-H. Ching $(\bowtie)$

University of South Florida Morsani College of Medicine, 1

Tampa General Circle, Suite H-012, Tampa, FL 33606, USA

e-mail: yching@outlook.com

E. M. Camporesi · D. Mangar

TEAMHealth/Florida Gulf-to-Bay Anesthesiology Associates, 1

Tampa General Circle, Suite C-208, Tampa, FL 33606, USA 